\title{
Environmental and Social Factors Supplemental Qualifiers Dataset
}

National Cancer Institute

\section{Source}

National Cancer Institute. Environmental and Social Factors Supplemental Qualifiers

Dataset. NCl Thesaurus. Code C147210.

A dataset containing supplemental information, specifically non-standard variables, to parent records in the environmental and social factors domain. 